\title{
Nonlinear Optical Studies of DNA Doped Rhodamine 6G-PVA Films Using Picosecond Pulses
}

\author{
Sasidharan Sreeja ${ }^{1}$, Balan Nityaja ${ }^{1}$, Debasis Swain ${ }^{2}$, \\ Vadakkedathu Parameswaran Narayana Nampoori ${ }^{1}$, Padmanabhan Radhakrishnan ${ }^{1}$, \\ Soma Venugopal Rao ${ }^{2^{*}}$ \\ ${ }^{1}$ International School of Photonics, Cochin University of Science and Technology, Cochin, India \\ ${ }^{2}$ Advanced Centre of Research in High Energy Materials (ACRHEM), \\ University of Hyderabad, Hyderabad, India \\ Email: *svrsp@uohyd.ernet.in, soma_venu@yahoo.com
}

Received May 30, 2012; revised June 28, 2012; accepted July 10, 2012

\begin{abstract}
We present our results from the measurements of third-order optical nonlinearity in DNA doped Rhodamine 6G/PVA films achieved through Z-scan measurements using $\sim 2$ picosecond (ps) pulses at a wavelength of $800 \mathrm{~nm}$. The films demonstrated negative nonlinear refractive index $\left(\mathrm{n}_{2}\right)$ with magnitudes of $(0.065-2.89) \times 10^{-14} \mathrm{~cm}^{2} / \mathrm{W}$ with varying concentration of DNA. Open aperture data demonstrated strong two-photon absorption with a magnitude of $\sim 1.6$ $\mathrm{cm} / \mathrm{GW}$ for films doped with $2 \mathrm{wt} \%$ of DNA. The recovery time of excited state population, retrieved from the degenerate pump-probe experimental data, was $<4$ ps. These data suggests that DNA is promising material for applications such as optical switching.
\end{abstract}

Keywords: DNA; Thin Films; Z-Scan; Picosecond; Two-Photon Absorption

\section{Introduction}

Deoxyribonucleic acid (DNA), a highly nonlinear bioorganic polymer, has been investigated as a photonic material recently with adequate success [1-14]. Biomaterials are interesting due to their remarkable properties which are not easily replicated with conventional organic or inorganic materials in the laboratory. Furthermore, natural biomaterials are a renewable resource and are inherently biodegradable [1]. Two DNA strands organize a DNA double helix through hydrogen bonds between the bases and are stabilized by $\pi-\pi$ interactions [2]. DNA in solid-state (thin-film) form has unique combination of optical and electronic properties, which forms the foundation of DNA photonics [3,4]. This potentially viable organic polymer has established various applications in organic light emitting diodes (OLED), organic thin film transistors, polymer electro-optic modulators, polymer lasers etc. [5,6]. OLEDs containing DNA electron blocking layers have been recently reported [7] to exhibit significant enhancement in luminance and luminous efficiency [8]. DNA-CTMA thin films doped with Sulphorhodamine (SRh) have been reported to exhibit photoluminescence intensity more than an order of magnitude higher than that of SRh in PMMA [10]. Dye doped DNA media have demonstrated amplified spontaneous emission with

\footnotetext{
${ }^{*}$ Corresponding author.
}

pulsed laser excitation [11]. Sznitko et al. [13] successfully demonstrated amplified spontaneous emission and lasing action in deoxyribonucleic acid blended with cetyltrimethyl-ammonium chloride surfactant and doped with 3-(1,1-dicyanoethenyl1)-1phenyl-4,5dihydro-1H-pyrazole organic dye. Hanczyc et al. [14] observed remarkable multiphoton absorption properties of DNA intercalating ruthenium complexes: 1) [Ru(phen)2 dppz $] 2^{+}$; 2) $[(11,11$ 'bidppz)(phen)4Ru2] $4^{+}$; 3) [11,11'-bipb(phen)4Ru2] $4^{+}$in the spectral range of 460 to $1100 \mathrm{~nm}$. Nonlinear optical (NLO) properties of DNA in solution form [15] and in silica films [16] has been investigated recently. Our group recently reported the NLO properties of Rhodamine 6G-PVA solutions doped with DNA where we observed saturable absorption (SA) at lower concentration of DNA and switching behavior at higher concentrations [17]. We expect completely different performance in thin film form and with shorter pulse excitation since the intersystem crossing rates are much slower compared to the pulse duration [18]. Moreover, for any novel nonlinear optical (NLO) materials investigated, one needs to apprehend the linear absorption, nonlinear absorption, and nonlinear refractive index magnitudes (in various forms such as thin films) to establish their potential in appropriate fields of interest. Herein, we present results on the NLO properties of DNA doped Rh6G-PVA films with Zscan technique using $\sim 2$ ps pulses recorded at a wavelength 
of $800 \mathrm{~nm}$. The sign and magnitude of nonlinear refractive index were derived from closed aperture Z-scan data. Open aperture Z-scan data revealed strong two photon absorption (TPA) in these films. Degenerate pumpprobe studies disclosed a fast response time of $\sim$ few $p s$.

\section{Materials and Methods}

We had used poly vinyl alcohol (PVA, Merck) for dissolving DNA and Rh6G. Since DNA and PVA are water soluble it is very easy to make thin films of DNA-PVA mixture. PVA solution acts a good matrix for hybridization of functional molecules and has excellent film forming, emulsifying, and adhesive properties. In the DNA-PVA system we have incorporated Rhodamine $6 \mathrm{G}$ owing to its high fluorescence quantum yield, low intersystem crossing rate, and little excited state absorption [18]. PVA solutions $(8 \mathrm{wt} \%)$ were prepared by dissolving appropriate amount of PVA in distilled water at $800^{\circ} \mathrm{C}$ under continuous stirring for $3 \mathrm{hr}$. Weighed DNA powder (SRL, extracted from herring sperm) was added to the prepared PVA solution. Rhodamine 6G dye was then added to PVA-DNA solution in desired concentration. After mixing (stirring) the solutions for $4 \mathrm{hr}$, thin films were fabricated on glass substrates using dip coating technique. Obtained films exhibited good optical transparency in the visible spectral range. The absorption spectra of prepared DNA films were characterized by using UV-VIS NIR spectrophotometer (Jasco V-570). Herewith, pure Rh6GPVA films are denoted as R6GPVA, DNA $1 \mathrm{wt} \%$ doped films are denoted as DNA1, and DNA $2 \mathrm{wt} \%$ doped films are denoted as DNA2.

\section{Experimental Techniques}

NLO measurements were performed on DNA1, DNA2 films with thickness of $\sim 100 \mu \mathrm{m}$. The Z-scan measurements [19] were performed using $\sim 2$ ps (FWHM, confirmed from independent autocorrelation experiments), $800 \mathrm{~nm}$ pulses with a repetition rate of $1 \mathrm{kHz}$ from an amplified Ti:sapphire system (Legend, Coherent). The beam waist $\left(2 \omega_{0}\right)$ at focal plane was estimated to be $\sim 60 \mu \mathrm{m}$ (FW1/ $\left.\mathrm{e}^{2} \mathrm{M}\right)$ with a corresponding Rayleigh range $(\mathrm{Zr})$ of $3.5 \pm$ $0.4 \mathrm{~mm}$ ensuring the validity of thin sample approximation. Complete details of the experimental set up can be found in our earlier publications [20-26].

\section{Results and Discussion}

Figure 1 illustrates the linear absorption spectra of DNA1 film and R6GPVA film. Figure 1(a) shows the presence absorption peak near $260 \mathrm{~nm}$ which is the characteristic of DNA. The peak is due to $\pi-\pi^{*}$ (where $\pi$ represents bonding orbitals and $\pi^{*}$ represents anti-bonding orbitals) transition of the electrons of $\mathrm{C}=\mathrm{C}$ bond in DNA bases [10]. The prominent absorption peak of Rh6G, near 532 nm, is evident from Figure 1(b).

Figure 2 illustrates the open aperture Z-scan data for DNA1 [(a) and (b)] and DNA2 [(c) and (d)] with different peak intensities $\left[110 \mathrm{GW} / \mathrm{cm}^{2}\right.$ for (a) and (c) $124 \mathrm{GW} / \mathrm{cm}^{2}$ for (b) and (d)]. We observed strong reverse saturable absorption (RSA) kind of behavior in the intensity range mentioned above. For higher peak intensities the sample was damaged (confirmed through the discoloring of the film). Obtained experimental data were fitted using equations for two-photon absorption (2PA, $\beta$ ) [20-25]. Solid (blue) lines in all the figures indicate theoretical fits. The fits from Figure 2(a) $\left(110 \mathrm{GW} / \mathrm{cm}^{2}\right)$ provided a $2 \mathrm{PA}$ coefficient of $0.45 \mathrm{~cm} / \mathrm{GW}$ and Figure 2(b) $\left(124 \mathrm{GW} / \mathrm{cm}^{2}\right)$ provided 2PA coefficient of $1.10 \mathrm{~cm} / \mathrm{GW}$ for DNA1. The magnitude of $\beta$ for DNA2 retrieved from the fits was $0.635 \mathrm{~cm} / \mathrm{GW}$ for $110 \mathrm{GW} / \mathrm{cm}^{2}$ and $1.61 \mathrm{~cm} / \mathrm{GW}$ for 124 $\mathrm{GW} / \mathrm{cm}^{2}$. The magnitude of $\beta$ in R6GPVA film was $<$ $0.25 \mathrm{~cm} / \mathrm{GW}$.

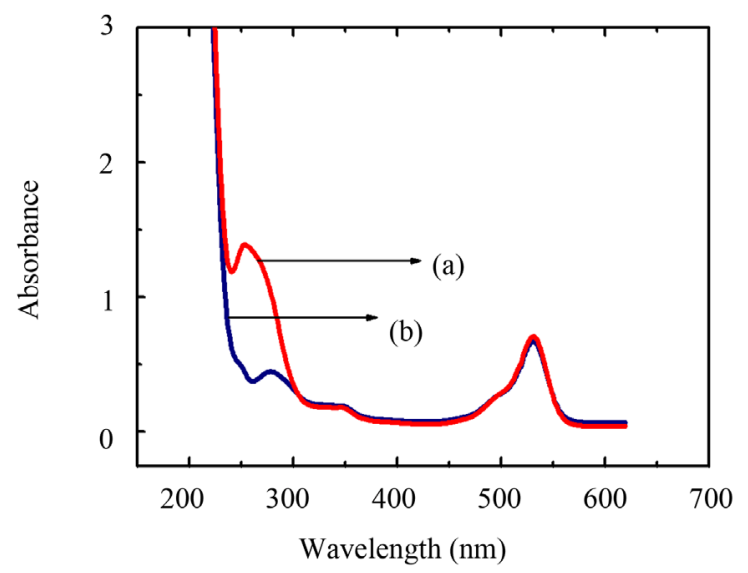

Figure 1. Absorption spectra and (a) DNA1 film (b) R6GPVA film.
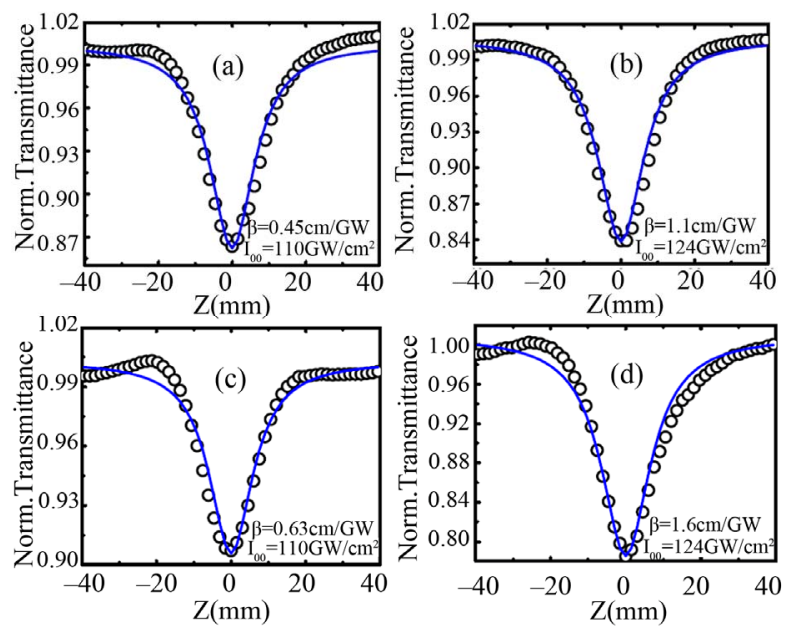

Figure 2. Open aperture $Z$ scan curves for (a) DNA1, 110 $\mathrm{GW} / \mathrm{cm}^{2}$; (b) DNA1, $124 \mathrm{GW} / \mathrm{cm}^{2}$; (c) DNA2, $110 \mathrm{GW} / \mathrm{cm}^{2}$; and (d) DNA2, $124 \mathrm{GW} / \mathrm{cm}^{2}$. Open circles indicate the experimental data while the solid (blue) lines indicate theoretical fits. 
Figures 3(a)-(c) demonstrate the typical closed aperture Z-scan curves obtained for DNA1, DNA2, and R6GPVA, respectively, recorded with a peak intensity of $\sim 110 \mathrm{GW} / \mathrm{cm}^{2}$. The data were fitted using standard equations [20-26]. It is apparent that all the samples demonstrated negative nonlinearity as indicated by the peak-valley signature. The magnitude of $\mathrm{n}_{2}$ was $\sim 4.61 \times$ $10^{-16} \mathrm{~cm}^{2} \cdot \mathrm{W}^{-1}$ for Rh6G doped PVA film. The magnitude of $\mathrm{n}_{2}$ for DNA1 was $\sim 6.5 \times 10^{-15} \mathrm{~cm}^{2} \cdot \mathrm{W}^{-1}$ while for that of DNA2 was $\sim 2.89 \times 10^{-14} \mathrm{~cm}^{2} \cdot \mathrm{W}^{-1}$. Both the magnitudes were higher than that of $\mathrm{n}_{2}$ recorded in R6GPVA. Enhancement in $n_{2}$ can be attributed to increase of charge transfer, which takes place in the system and is due to the presence of many highly polarizable conjugated $\pi$ electrons of DNA [17]. Moreover, the interactions due to intercalation into base pair stack at the core of double helix and/or insertion into the minor groove of DNA are documented to have strong impact on the optical characteristics. The magnitudes of $\mathrm{n}_{2}\left(10^{-14} \mathrm{~cm}^{2} \cdot \mathrm{W}^{-1}\right)$ obtained here are at least one order higher than those obtained in solution form $\left(10^{-14} \mathrm{~cm}^{2} \cdot \mathrm{W}^{-1}\right)$ using femtosecond pulses [15]. The magnitudes of 2PA coefficient obtained (1.61 $\mathrm{cm} / \mathrm{GW})$ are again higher than those obtained $(0.2$ $\mathrm{cm} / \mathrm{GW}$ ) in solutions [15]. Krupka et al. [27] obtained purely electronic, fast NLO susceptibility in a DNACTMA complex thin film with a third-order nonlinear optical susceptibility magnitude of $10^{-14}$ e.s.u. In our case the magnitudes of $\chi^{(3)}$ (third order nonlinear optical susceptibility) were estimated to be $8.45 \times 10^{-13}$ e.s.u. for DNA1 and $2.72 \times 10^{-12}$ e.s.u. for DNA2, respectively.

We had also performed the degenerate pump probe studies of DNA doped Rh6G + PVA films using $\sim 2$ ps pulses to evaluate the time response of the nonlinearity. Details of the experimental setup can be found in our earlier reference [23]. Figure 4 shows the data obtained indicating photo-induced absorption. A sharp fall in $\Delta \mathrm{T}$ was observed near zero delay followed by a quick recovery. The recovery time of population from the excited states was estimated to be $\sim 4.2 \mathrm{ps}$. The obtained lifetime is in agreement with the non-radiative decay times observed in DNA model systems measured by Kohler et al. [28] using ultrashort pulses. Our future studies will focus on evaluating the nonlinearities at different wavelengths in the visible/near-IR spectral regions.

\section{Conclusion}

To summarize, we deliberated the NLO properties of thin films of Rhodamine 6G, doped with DNA, obtained using ps pulses. The addition of DNA enhanced the NLO properties of thin films. We identified that the films demonstrated negative $n_{2}$ with a highest magnitude of $2.89 \times$ $10^{-14} \mathrm{~cm}^{2} / \mathrm{W}$ for DNA2 films. Open aperture data demonstrated strong 2PA with a highest magnitude of $\sim 1.6$ $\mathrm{cm} / \mathrm{GW}$, again for DNA2 films. Ultrafast response ob-
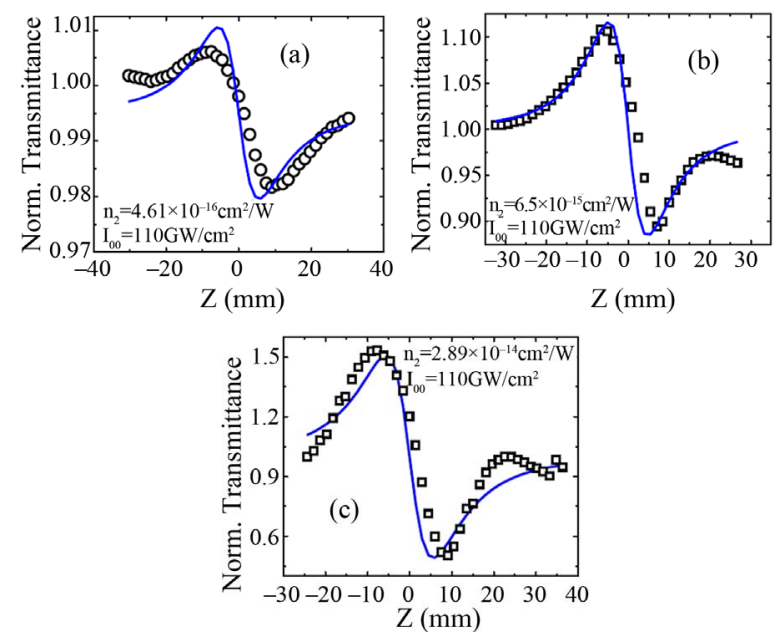

Figure 3. Closed aperture Z-scan curves for (a) R6GPVA film, (b) DNA1 film, and (c) DNA2 film. Circles/squares represent the data while the solid (blue) lines indicate theoretical fits.

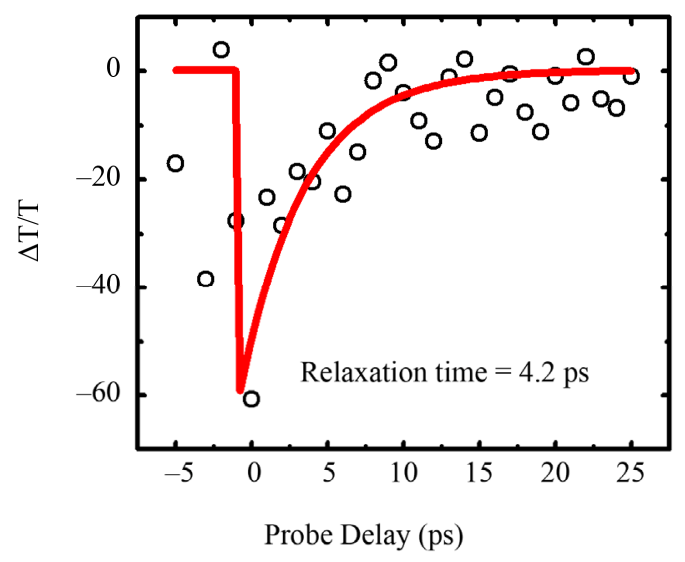

Figure 4. Degenerate pump-probe data of DNA2 film recorded at $800 \mathrm{~nm}$.

tained from pump-probe experiments suggests that thismaterial has potential for applications in photonics. We conclude that PVA is a good matrix for fluorescent dyes incorporated into the double helix of DNA molecule enabling them suitable for practical applications in optical devices.

\section{Acknowledgements}

Financial support from DRDO is greatly acknowledged. S. Sreeja acknowledges UGC for the financial assistance.

\section{REFERENCES}

[1] P. N. Prasad, "Introduction to Bio-Photonics," Wiley, New York, 2003.

[2] N. Kitazawa, S. Miyagawa, K. Date, W. Aroonjaeng, M. Aono and Y. Watanabe, "Optical Properties of Dye-Doped Deoxyribonucleic Acid Films," Journal of Materials Science, Vol. 44, No. 18, 2009, pp. 4999-5003. 
doi:10.1007/s10853-009-3764-5

[3] A. J. Steckl, "DNA-A New Material for Photonics?" Nature Photonics, Vol. 1, No. 1, 2007, pp. 3-5. doi:10.1038/nphoton.2006.56

[4] J. G. Grote, E. M. Heckman, D. Diggs, J. A. Hagen, P. Yaney, A. J. Steckl, G. S. He, Q. Zheng, P. N. Prasad, J. Zetts and F. K. Hopkins, "DNA-Based Materials for Electro-Optic Applications," Proceedings of SPIE, Vol. 5934, 2005, pp. 38-43. doi:10.1117/12.615206

[5] A. J. Steckl, H. Spaeth, H. You, E. Gomez and J. Grote, "DNA as an Optical Material," Optics and Photonics News, Vol. 22, No. 7, 2011, pp. 34-39. doi:10.1364/OPN.22.7.000034

[6] A. J. Steckl, A. Hagen, Z. Yu, R. A. Jones, W. Li, D. Han, D. Y. Kim and H. Spaeth, "Challenges and Opportunities for Biophotonic Devices in the Liquid State and the Solid State," IEEE Nanotechnology Conference, Vol. 1, 2006, pp. 159-161. doi:10.1109/NANO.2006.247596

[7] J. A. Hagen, W. Li and A. J. Steckl and J. G. Grote, "Enhanced Emission Efficiency in Organic Light-Emitting Diodes Using Deoxyribonucleic Acid Complex as an Electron Blocking Layer," Applied Physics Letters, Vol. 88, No. 17, 2006, Article ID: 171109. doi:10.1063/1.2197973

[8] Z. Yu, W. Li, J. A. Hagen, Y. Zhou, D. Klotzkin, J. G. Grote and A. J. Steckl, "Photoluminescence and Lasing from Deoxyribonucleic Acid (DNA) Thin Films Doped with Sulforhodamine," Applied Optics, Vol. 46, No. 9, 2007, pp. 1507-1513. doi:10.1364/AO.46.001507

[9] Y. Kawabe, L. Wang, S. Horinouchi and N. Ogata, "Amplified Spontaneous Emission from Fluorescent-DyeDoped DNA-Surfactant Complex Films," Advanced Materials, Vol. 12, No. 17, 2000, pp. 1281-1283. doi:10.1002/1521-4095(200009)12:17<1281::AID-ADM $\underline{\mathrm{A} 1281>3.0 . \mathrm{CO} ; 2-0}$

[10] J. Grote, D. Y. Zang, F. Ouchen, G. Subramanyam, P. Yaney, C. Bartsch, E. Heckman and R. Naik, "Progress of DNA Photonics," Proceedings of SPIE, Vol. 7765, 2010, Article ID: 776502. doi:10.1117/12.862160

[11] N. Balan, M. Hari and V. P. N. Nampoori, "Selective Mode Excitation in Dye-Doped DNA Polyvinyl Alcohol Thin Film," Applied Optics, Vol. 48, No. 19, 2009, pp. 3521-3525. doi:10.1364/AO.48.003521

[12] B. Sahraoui, M. Pranaitis, D. Gindre, J. Niziol and V. Kažukauskas, "Opportunities of Deoxyribonucleic Acid Complexes Composites for Nonlinear Optical Applications," Journal of Applied Physics, Vol. 110, No. 8, 2011, Article ID: 083117. doi:10.1063/1.3655985

[13] L. Sznitko, J. Mysliwiec, P. Karpinski, K. Palewska, K. Parafiniuk, S. Bartkiewicz, I. Rau, F. Kajzar and A. Miniewicz, "Biopolymer Based System Doped with NonLinear Optical Dye as a Medium for Amplified Spontaneous Emission and Lasing," Applied Physics Letters, Vol. 99, No. 3, 2011, Article ID: 031107. doi:10.1063/1.3610566

[14] P. Hanczyc, B. Norden and M. Samoc, "Two-Photon Absorption of Metal-Organic DNA-Probes," Dalton Transactions, Vol. 41, No. 11, 2012, pp. 3123-3125. doi:10.1039/c2dt12264b
[15] M. Samoc, A. Samoc and J. G. Grote, "Complex Nonlinear Refractive Index of DNA," Chemical Physics Letters, Vol. 431, No. 1-3, 2006, pp. 132-134. doi:10.1016/i.cplett.2006.09.057

[16] B. Sahraoui, M. Pranaitis, K. Iliopoulos, M. Mihaly, A. F. Comanescu, M. Moldoveanu, I. Rau and V. Kažukauskas, "Enhancement of Linear and Nonlinear Optical Properties of Deoxyribonucleic Acid-Silica Thin Films Doped with Rhodamine," Applied Physics Letters, Vol. 99, No. 24, 2011, Article ID: 243304. doi:10.1063/1.3669406

[17] B. Nithyaja, H. Misha, P. Radhakrishnan and V. P. N. Nampoori, "Effect of Deoxyribonucleic Acid on Nonlinear Optical Properties of Rhodamine 6G-Polyvinyl Alcohol Solution," Journal of Applied Physics, Vol. 109, No. 2, 2011, Article ID: 023110. doi:10.1063/1.3520657

[18] C. V. Bindhu, S. S. Harilal, V. P. N. Nampoori and C. P. G. Vallabhan, "Studies of Nonlinear Absorption and Aggregation in Aqueous Solutions of Rhodamine 6G Using Transient Thermal Lens Technique," Journal of Physics D: Applied Physics, Vol. 32, No. 4, 1999, pp. 407-411. doi:10.1088/0022-3727/32/4/009

[19] M. Sheik-Bahae, A. A. Said, T. H. Wei, D. J. Hagan and E. W. Van Stryland, "Sensitive Measurement of Optical Nonlinearities Using a Single Beam," IEEE Journal of Quantum Electronics, Vol. 26, No. 4, 1999, pp. 760-769. doi:10.1109/3.53394

[20] S. Venugopal Rao, T. Shuvan Prashant, T. Sarma, P. K. Panda, D. Swain and S. P. Tewari, "Two-Photon and ThreePhoton Absorption in Dinapthoporphycenes," Chemical Physics Letters, Vol. 514, No. 1-3, 2011, pp. 98-103. doi:10.1016/j.cplett.2011.08.021

[21] S. Venugopal Rao, "Large Picosecond Nonlinearity in Gold Nanoparticles Synthesized Using Coriander Leaves (Coriandrum sativum)," Journal of Modern Optics, Vol. 58, No. 12, 2011, pp. 1024-1049. doi:10.1080/09500340.2011.590903

[22] P. T. Anusha, P. Silviya Reeta, L. Giribabu, S. P. Tewari and S. Venugopal Rao, "Picosecond Optical Nonlinearities of Unsymmetrical Alkyl and Alkoxy Phthalocyanines Studied Using the Z-Scan Technique," Materials Letters, Vol. 64, No. 17, 2010, pp. 1915-1917. doi:10.1016/j.matlet.2010.06.004

[23] D. Swain, P. T. Anusha, T. Shuvan Prashant, S. P. Tewari, T. Sarma, P. K. Panda and S. Venugopal Rao, "Ultrafast Excited State Dynamics and Dispersion Studies of Nonlinear Optical Properties in Dinaphthoporphycenes," Applied Physics Letters, Vol. 100, No. 14, 2012, Article ID: 141109. doi:10.1063/1.3701274

[24] S. Hamad, S. P. Tewari, L. Giribabu and S. Venugopal Rao, "Picosecond and Femtosecond Optical Nonlinearities of Novel Corroles," Journal of Porphyrins and Phthalocyanines, Vol. 16, No. 1, 2012, pp. 140-148. doi: $10.1063 / 1.3643648$

[25] K. Venkata Saravanan, K. C. James Raju, M. Ghanashyam Krishna, S. P. Tewari and S. Venugopal Rao, "Large Three-Photon Absorption in $\mathrm{Ba}_{0.5} \mathrm{Sr}_{0.5} \mathrm{TiO}_{3}$ Films Studied Using Z-Scan Technique," Applied Physics Letters, Vol. 96, No. 23, 2010, Article ID: 232905. doi: $10.1063 / 1.3447930$ 
[26] G. Krishna Podagatlapalli, S. Hamad, S. Sreedhar, S. P. Tewari and S. Venugopal Rao, "Fabrication and Characterization of Aluminum Nanostructures and Nanoparticles Obtained Using Femtosecond Ablation Technique," Chemical Physics Letters, Vol. 530, 2012, pp. 93-97. doi:10.1016/j.cplett.2012.01.081

[27] O. Krupka, A. El-Ghayoury, I. Rau, B. Sahraoui, J. G.
Grote and F. Kajzar, "NLO Properties of Functionalized DNA Thin Films," Thin Solid Films, Vol. 516, No. 24, 2008, pp. 8932-8936. doi:10.1016/j.tsf.2007.11.089

[28] B. Kohler, "Nonradiative Decay Mechanisms in DNA Model Systems," Journal of Physical Chemistry Letters, 1, No. 13, 2010, pp. 2047-2053. doi:10.1021/jz100491x 